\title{
El papel del fuego en los enterramientos neolíticos finales/ calcolíticos iniciales de los abrigos de la Sierra de Cantabria y sus estribaciones (valle medio-alto del Ebro)
}

\author{
The role of fire in the Late Neolithic/Early Chalcolithic burial rockshelters of the Sierra de \\ Cantabria mountain range and its foothills (mid-upper Ebro valley)
}

\section{Teresa Fernández-Crespo ${ }^{\text {ab }}$}

\section{RESUMEN}

Se analizan las evidencias de fuego en los restos humanos de cinco abrigos bajo roca de la Sierra de Cantabria y sus estribaciones utilizados durante el Neolítico final/Calcolítico inicial como lugares de enterramiento (Las Yurdinas II, Los Husos I, Los Husos II, Peña Larga y La Peña de Marañón) a través de parámetros definidos a partir de la experimentación forense. Los resultados muestran una cercanía temporal entre el depósito y la cremación de los cuerpos o restos en las sepulturas de Los Husos II y La Peña de Marañón, observándose características propias de una quema "en fresco" en los huesos. En los demás sitios las evidencias se relacionan con una quema "en seco". Se propone, al menos para los primeros casos, relacionar el uso del fuego con procesos de clausura de la trayectoria funeraria del lugar. No se descarta en cambio una posible naturaleza accidental del fuego en los demás depósitos.

\begin{abstract}
The traces of fire affecting human bones from five Late Neolithic/Early Chalcolithic burial rockshelters of the Sierra de Cantabria and its foothills (Las Yurdinas II, Los Husos I, Los Husos II, Peña Larga and La Peña de Marañon) are analysed through parameters determined by forensic experimentation. The results show that in some burials (Los Husos II, La Peña de Marañón) little time elapsed between the deposit and the cremation of the
\end{abstract}

bodies. This is consistent with in situ burning when bones still were 'fresh' and suggests that cremation was related to the intentional closing of burial use of the sites. In other cave deposits, however, fire appears to be applied to dry bones. Unintentional fire cannot be rejected as an explanation of the evidence in the latter cases.

Palabras clave: Evidencias de fuego; Cremaciones; Experimentación forense; Abrigos funerarios; Neolítico final/ Calcolítico inicial; Sierra de Cantabria; Valle medio-alto del Ebro.

Key words: Traces of fire; Cremation; Forensic experimentation; Burial rockshelters; Late Neolithic/Early Chalcolithic; Sierra de Cantabria; Mid-upper Ebro valley.

\section{INTRODUCCIÓN}

Los huesos quemados han sido tradicionalmente considerados "una suerte de material inclasificable más, ocupante de espacios siempre escasos en almacenes, cuando no simple desecho" (Gómez Bellard 1996: 55). En las últimas décadas, de modo aún infrecuente pero fiable, la Arqueología ha comenzado a apreciar el valor de las cremaciones como fuente de información de distintos aspectos poblacionales y sobre todo rituales de las sociedades pretéritas (Rojo y Kunst 2002).

a Dpto. de Genética, Antropología Física y Fisiología Animal. Universidad del País Vasco (UPV/EHU). B ${ }^{\circ}$ Sarriena s/n. 48940 Leioa. España. Correo e.: teresa.fernandezc@ehu.es

${ }^{b}$ Research Laboratory for Archaeology and the History of Art, University of Oxford. South Parks Road. OX1 3QY Oxford. United Kingdom. Correo e.: teresa.fernandez-crespo@rlaha.ox.ac.uk

Recibido 15-X-2015; aceptado 14-XII-2015. 
Así las cosas, este artículo pretende analizar a través de protocolos definidos por la experimentación forense la presencia de huesos humanos quemados en cinco abrigos con depósitos funerarios neolíticos finales/calcolíticos iniciales de la Sierra de Cantabria y sus estribaciones (Las Yurdinas II, Los Husos I, Los Husos II, Peña Larga y La Peña de Marañón,) con el fin de determinar el carácter accidental o deliberado (sea ritual o no) de los hallazgos.

\section{CONTEXTO}

El Neolítico final/Calcolítico inicial de la Sierra de Cantabria y sus estribaciones (ca. 37002900 cal. BC) se caracteriza esencialmente por la presencia de tumbas megalíticas y por la proliferación de enterramientos bajo roca (Fig. 1). Esta novedad funeraria es quizá resultado del aumento de las poblaciones que, en el ambiente montañoso en que las cuevas aparecen, pueden desarrollar la

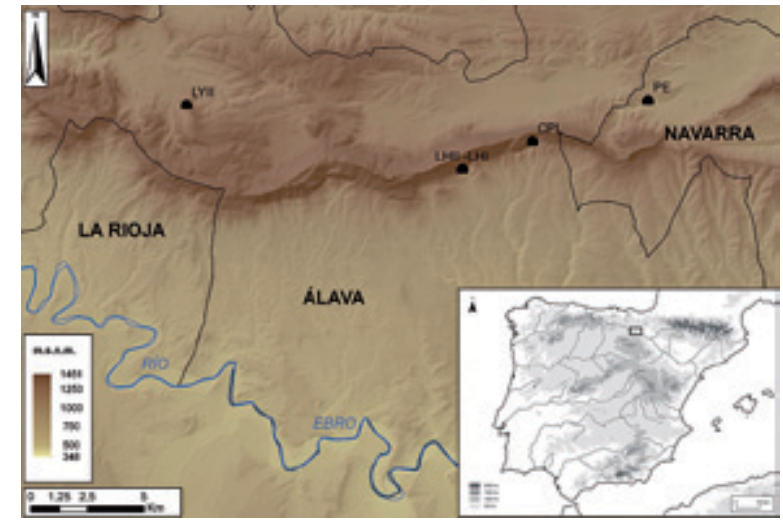

Fig. 1. Localización de los depósitos funerarios en cueva analizados en el trabajo (UTM, ETRS89, 30T): LYII: Las Yurdinas II $(X=524.500, Y=4.719 .600)$; LHI: Los Husos I $(X=536.800, Y=4.716 .750)$; LHII: Los Husos II $(X=536.700, Y=4.716 .750)$; $C P L$ : Peña Larga $(X=539.800, Y=4.718 .000) ; P E$ : La Peña de Marañón $(X=544.900, Y=4.719 .700)$. Fuentes cartográficas: hojas digitales 170, 171, 203 y 204 del MTN25 vectorial (eds. 2003-2008) y MDT25 (ed. 2010) del Instituto Geográfico Nacional de España.

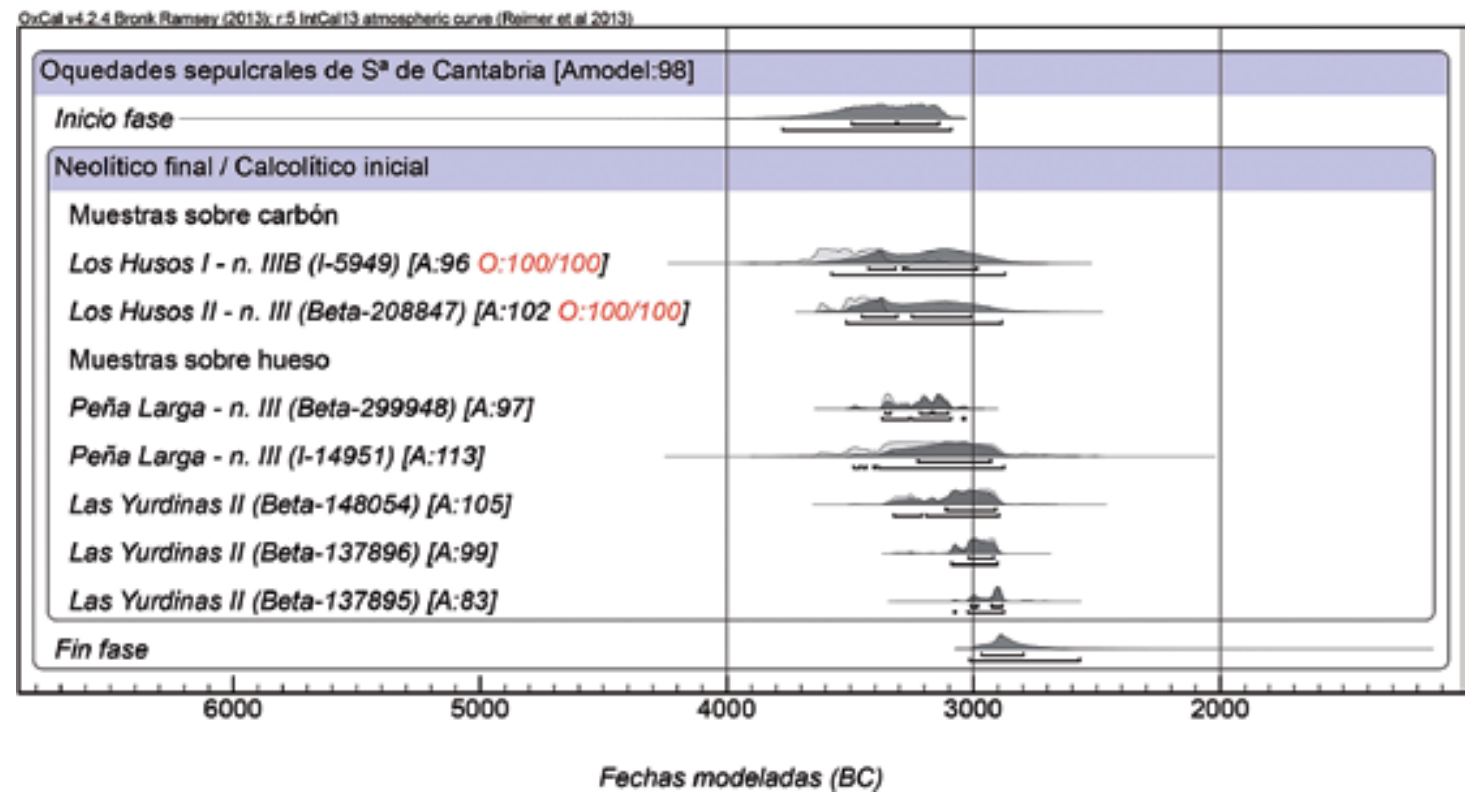

Fig. 2. Dataciones disponibles para los depósitos analizados en la Sierra de Cantabria (Los Husos I, Apellániz 1974: 194; Los Husos II, Fernández Eraso 2006: 49; Las Yurdinas II, Fernández Eraso 2003: 165; Peña Larga, Fernández Eraso 1997: 161; Fernández Eraso y Mujika 2013: 104; Rofes et al. 2013: 159), calibradas y modeladas mediante estadística bayesiana a partir de OxCal v4.2.3 (Bronk Ramsey 2009; Reimer et al. 2013). El modelo incluido permite observar si la correspondencia de las fechas - por su cercanía- con una fase o periodo relativamente restringido se sostiene estadísticamente, mostrando en este caso un nivel de aceptación muy alto tanto desde un punto de vista general $\left(\mathrm{A}_{\text {model }}=98 \%\right)$ como en lo que respecta a cada una de las fechas por separado ("A:x"). El modelo tiene además en cuenta el posible envejecimiento de las fechas obtenidas sobre carbón (indicado mediante la expresión "O:100/100”). 
especialización pastoril como excelente medio de explotación de esos territorios, en la ya asentada economía productora (Andrés 2009: 20).

En este contexto, abrigos y cuevas actúan como depósitos eminentemente primarios, acumulativos y definitivos -al igual que los dólmenes (Fernández-Crespo y de la Rúa 2005)-, pese a que los restos óseos que acogen se encuentren a menudo en estado desordenado y fragmentario y muestren signos de cremación.

La cultura material asociada (fragmentos cerámicos lisos o con decoración poco elaborada, herramientas líticas - puntas de flecha, raederas, piezas de hoz...-, algún objeto óseo -generalmente punzones y espátulas- y contados elementos de adorno) y las dataciones absolutas disponibles no dejan lugar a duda sobre la adscripción del episodio funerario de todas ellas al mencionado periodo (Fig. 2).

\section{MATERIAL Y MÉTODOS}

La correcta interpretación del papel del fuego en los abrigos sepulcrales de la Sierra de Cantabria y sus estribaciones a través del estudio de los restos óseos humanos es compleja. Los aspectos más ampliamente tratados para resolver este interrogante han sido, además de obvias observaciones de campo relativas a la identificación de conexiones anatómicas lábiles o el correcto equilibrio entre piezas anatómicas (Duday et al. 1990), el estudio del estado de los restos en el momento de su exposición al fuego ("en fresco", es decir, con tejidos blandos o recientemente descarnados; y "en seco" o totalmente esqueletizados) y la estimación de la temperatura alcanzada durante la combustión.

La morfología de las fisuras y las deformaciones son consideradas por la mayoría de los autores como los mejores criterios diagnósticos del estado de los huesos, pese a no aparecer siempre claramente definidas en aquéllos calcinados (Baby 1954; Gejvall 1969; Binford 1972; Thurman y Willmore 1981; Shipman et al. 1984; Ubelaker 2007). En esencia, puede decirse que la superficie de un hueso quemado "en fresco" o con carne adoptará un aspecto liso y vítreo y un sonido especial al ser golpeado (casi metálico) y mostrará deformaciones pronunciadas, una alta intensidad de fragmentación y una muy particu- lar localización de estrías y fracturas (Baby 1954; Binford 1972). Grosso modo, seguirán patrones: a) transversales y de tendencia curvilínea o concéntrica al eje mayor en los huesos, a veces también longitudinales de morfología irregular; b) paralelos, pentagonales y estriados por grietas profundas en las superficies convexas y c) estriados en las cóncavas y planas y en zonas de menor resistencia (Reverte 1991). Autores como M. Thurman y L. J. Willmore (1981: 281) proponen las mismas diferencias entre el hueso fresco y el seco, pero añaden una nueva categoría: el hueso recientemente descarnado o "en verde" que, según éstos, básicamente exhibirá un patrón de agrietamiento y deformidad similar al del hueso fresco pero menos pronunciado. Otros, en cambio, creen poco fiables estos criterios y erigen como único rasgo verdaderamente distintivo entre el material calcinado "en verde" y "en fresco" la observación de anillos concéntricos -principalmente en la región poplítea del fémur-(Buikstra y Swegle 1989: 256) o de secuencias de grietas de apariencia curvilínea (Symes et al. 2008: 43) en el tejido óseo, entendiéndolas como resultado de distintos procesos de retracción de los tejidos blandos y el periostio del hueso durante la cremación. Estas observaciones, sin embargo, rara vez pueden ser percibidas macroscópicamente sobre el material antropológico. Por ello es metodológicamente más sencillo asumir una sola categoría que incluya tanto aquellos

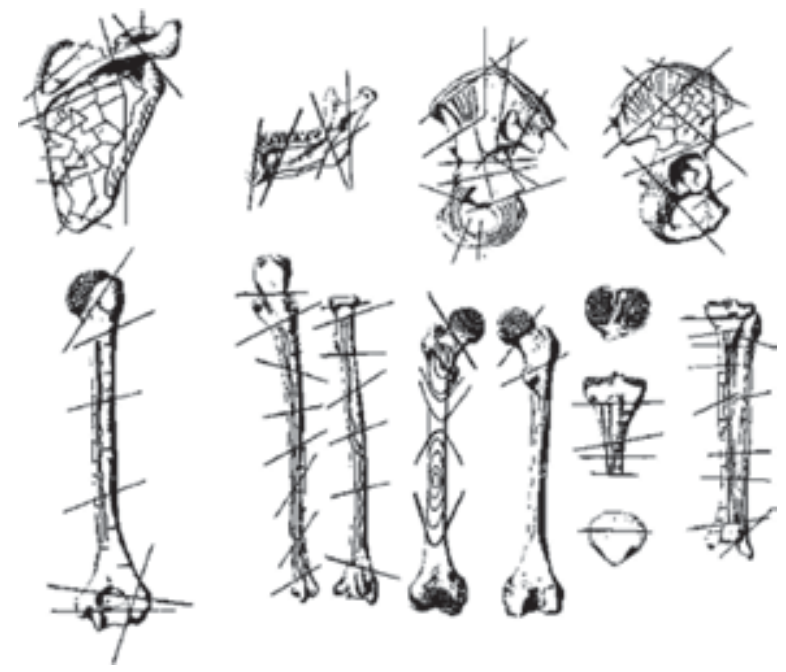

Fig. 3. Principales zonas de menor resistencia del hueso al fuego -loci minoris resistentiae- (modificado a partir de Reverte 1991: 861). 


\section{RELACIÓN ENTRE COLORACIÓN Y TEMPERATURA EN LAS CREMACIONES SEGÚN DISTINTOS ESTUDIOS DE EXPERIMENTACIÓN FORENSE}

\begin{tabular}{|c|c|c|c|c|c|c|c|c|}
\hline & lutor/es & $\begin{array}{c}\text { Bonucci y } \\
\text { Graziani } \\
1975\end{array}$ & Holck 1986 & $\begin{array}{c}\text { Hummel et } \\
\text { al. } 1988\end{array}$ & Mays 1998 & $\begin{array}{c}\text { Shipman et } \\
\text { al. } 1984\end{array}$ & $\begin{array}{c}\text { Susini et al. } \\
1988\end{array}$ & Wahl 1981 \\
\hline & Material & $\begin{array}{l}\text { Bóvido } \\
\text { fresco }\end{array}$ & Humano & Humano & $\begin{array}{l}\text { Cáprido } \\
\text { fresco }\end{array}$ & $\begin{array}{l}\text { Ovicáprido } \\
\text { reciente }\end{array}$ & Humano & Humano \\
\hline & $<200$ & & natural & amarillo & naranja & & & blanco \\
\hline & $200-250$ & & & & rojo & natural & & \\
\hline & $250-300$ & amarrillo & gins & marrón & marrón & amarillo & amanno & Han \\
\hline & $300-350$ & marron & & & & & marrón & marrón \\
\hline & $350-400$ & negro & neoro. & negro & negro & & negro & \\
\hline & $400-450$ & & & & & rojizo & & \\
\hline & $450-500$ & & & & & marrón & & marrón \\
\hline & $500-550$ & & & negro & gris & gris oscuro & gris oscuro & negro \\
\hline $\mathrm{T}$ & $550-600$ & gins & & & & & & \\
\hline$\left({ }^{\circ} \mathrm{C}\right)$ & $600-650$ & & gris claro & gris azul & & negro & gris beige & \\
\hline & $650-700$ & & & & & azul & & \\
\hline & $700-750$ & & & gris & & & gris trato & gins dau \\
\hline & $750-800$ & & & gris claro & & & & \\
\hline & $800-850$ & & & & & azul & & \\
\hline & $850-900$ & blanco & & & & gris claro & & \\
\hline & $900-950$ & & & blanco & Dianco & blanco & & \\
\hline & $950-1000$ & & & & & & & \\
\hline & $>1000$ & & & & & & & \\
\hline
\end{tabular}

Fig. 4. Relación entre temperatura de combustión $\left({ }^{\circ} \mathrm{C}\right)$ y coloración resultante en los huesos a partir de diferentes trabajos de experimentación forense.

restos afectados por el fuego cuando conservaban tejidos blandos como aquéllos que lo fueron recientemente esqueletizados. Considerando que en ambos casos queda implícita la cercanía entre el momento de la muerte y la aplicación del fuego, sólo se hablará de hueso quemado "en fresco" en el presente trabajo. En cambio, un hueso quemado "en seco" adquirirá un aspecto harinoso (que pue- de llegar a ser pulverulento) y manifestará fisuras y grietas profundas y longitudinales, con craquelados superficiales y/o de tipo paralelo-transversal, sin deformación o torsión de la estructura (Fig. 3).

Al estimar la temperatura de combustión, la mayoría de los autores ven cierta concordancia entre la coloración de los huesos y la temperatura a la que fueron sometidos (Shipman et al. 1984; 
Herrmann 1988), pese que unos pocos (Dutour et al. 1989: 23-28) han puesto en duda esta relación apoyándose en experiencias, todo sea dicho, basadas en una muestra muy limitada. La sucesión de colores observada es muy diversa, en esencia, natural-amarillento, rojizo, marrón, marrón oscuro, negro, gris azulado, gris claro, blanco. Las intensidades de las temperaturas suelen variar aproximadamente cada $150^{\circ} \mathrm{C}$, con independencia de que los huesos sometidos a estudio sean humanos o de animales (Bonucci y Graziani 1975; Herrmann 1976; Wahl 1981; Holck 1986; Shipman et al. 1984; Hummel et al. 1988; Susini et al. 1988; Mays 1998) (Fig. 4).

\section{ABRIGOS SEPULCRALES Y SIGNOS DE FUEGO. VALORACIÓN E INTERPRETA- CIÓN DE LOS HALLAZGOS}

\subsection{Las Yurdinas II (Peñacerrada, Álava)}

\subsubsection{Presentación del sitio}

Las Yurdinas II es un abrigo localizado en las estribaciones septentrionales de la Sierra de Cantabria donde se identificaron dos pinturas rojas que representan una mujer y un bóvido (Sáenz de Buruaga et al. 1991/1992) y en cuya pared norte se abre una sima que guardaba un depósito funerario. En 1970 se reconoció como sitio arqueológico, pero no se excavó hasta el año 2000 (Fernández Eraso 2003). Durante las campañas de excavación se identificó un único nivel arqueológico, dividido en tres capas (I a III) (Fig. 5a), que acogía los restos de casi un centenar de sujetos en un estado de casi total desorden y mínimamente afectados por el fuego (Fig. 5b). En los escasos ajuares recuperados destacan casi una veintena de puntas de flecha y algunos adornos sobre concha y piedra. La cronología absoluta se basa en tres muestras óseas humanas de la capa superior, media y base del depósito tomadas durante los trabajos de campo y datadas respectivamente en 4390 $\pm 80 \mathrm{BP}$ (3339-2891 cal.

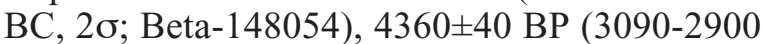

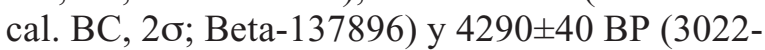

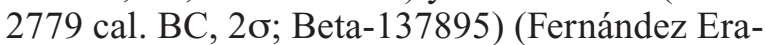
so 2003$)$.
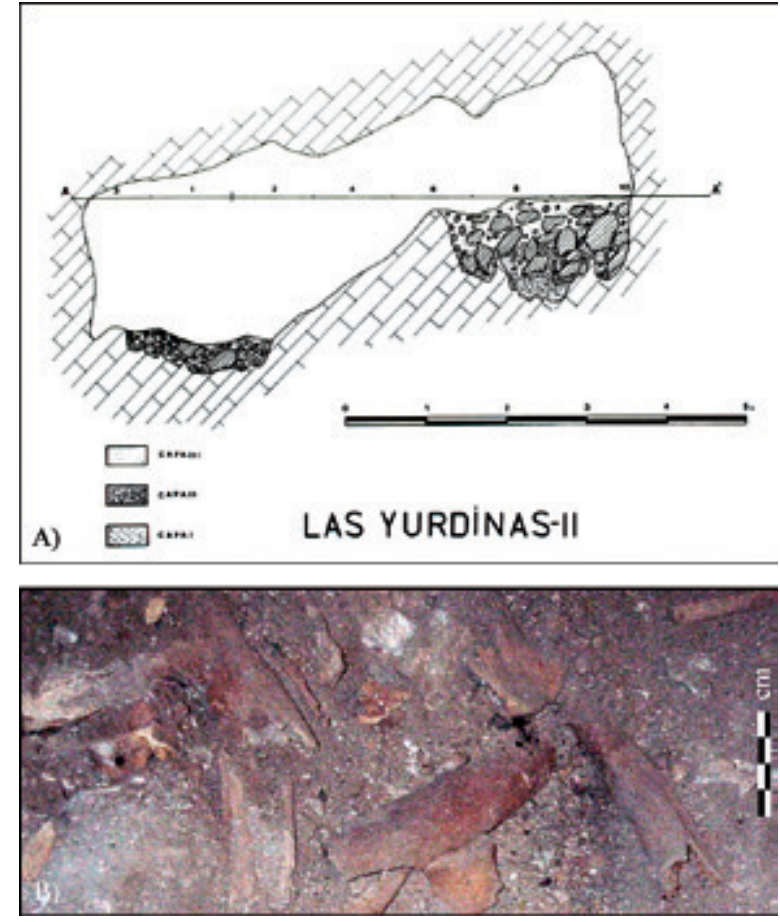

Fig. 5. Sima de Las Yurdinas II: A) Sección con referencia a las capas del nivel funerario (modificado a partir de Fernández Eraso 2003: 39); B) Fotografía de restos humanos en superficie con signos de fuego (modificado a partir de Fernández Eraso 2003: 38).

\subsubsection{Características de la muestra ósea humana}

Las Yurdinas II acoge un enterramiento múltiple acumulativo. La presencia de todas las porciones anatómicas (excepto ciertos pequeños huesos de la cara y el oído) y de segmentos óseos relativamente lábiles (como el vertebral) en conexión abogan por un muy probable tratamiento primario. Como suele ocurrir en estos casos, la alta fragmentación y la desarticulación generalizada del material antropológico, junto a la incidencia de determinados procesos tafonómicos (destacando los depósitos cálcicos y los signos de fuego en los huesos), han sido los máximos responsables de las limitaciones en el proceso de identificación ósea.

El número mínimo de 90 individuos (NMI) se ha estimado mediante el recuento de las escápulas para los infantiles I y II (0-6 años y 7-12 años, respectivamente), y de las mandíbulas para los juveniles (13-19 años) y adultos (> 20 años). De ellos, 37 eran subadultos ( 2 fetos, 16 infantiles I, 10 infantiles II y 9 juveniles), según el desarrollo

Trab. Prehist., 73, N. ${ }^{\circ}$ 1, enero-junio 2016, pp. 128-146, ISSN: 0082-5638

doi: $10.3989 /$ tp.2016.12167 
dental y esquelético (Ubelaker 1989; Scheuer y Black 2000), y 53 adultos (28 jóvenes, 4 maduros, 2 seniles y 19 de edad indeterminada), según el desgaste de las piezas dentarias de las mandíbulas (Brothwell 1965). Por la morfología de los maxilares inferiores (Ferembach et al. 1980) se reconocieron 17 varones y 30 mujeres entre los adultos y juveniles (siendo el resto alofisos o intederminados).

\subsubsection{Análisis de las cremaciones}

Se han hallado evidencias de fuego en menos del $20 \%$ de los cerca de 40.000 elementos óseos identificables que componen la colección de Las Yurdinas II. Los huesos están afectados de modo mínimo y muy desigual, apreciándose manchas negruzcas, en mayor o menor intensidad, y también algunas parduscas, vinculables a una quema somera a temperaturas no muy altas. El análisis del proceso pirolítico aboga por una quema "en seco" de los restos, una vez perdidas sus partes blandas (Guillon 1986). Muy posiblemente fue accidental, dado el aspecto pulverulento, la coloración propia de temperaturas no muy altas, las escasas contracción y fragmentación, y el patrón de fracturas, en general paralelo/transversal al eje mayor que evidencian.

Este hecho, según J. Fernández Eraso (2003: 39), "no parece tener relación con costumbres similares, detectadas en otros yacimientos de la misma época, destinadas a la higiene del lugar" o a otras prácticas burocrático-rituales, y podría entenderse como posible resultado de "una tea arrojada en época no muy antigua, que llegó a prender sólo en las materias vegetales localizadas bajo la grieta" afectando a la parte de los huesos no cubierta por el sedimento.

\subsection{Los Husos I (Elvillar, Álava)}

\subsubsection{Presentación del sitio}

El abrigo de Los Husos I se abre a los pies de un gran farallón calizo, en la vertiente sur de la Sierra de Cantabria. Fue descubierto en 1964 por I. Amezua. J. M. Apellániz (1974) lo excavó en parte de 1965 hasta 1970 y J. Fernández Eraso (2007/2008) lo revisó entre 1999 y 2001. El uso funerario del sitio se circunscribe al nivel III, excavado por el primero y dividido en dos subniveles A y B. Del subnivel IIIB se dató un trozo de madera carbonizada en $4730 \pm 110$ BP (37633114 cal. BC, 20; I-59494) (Apellániz 1974). En él se depositaron casi una veintena de individuos, cuyos restos se encontraban muy fragmentados, desordenados y en ocasiones quemados, junto con varias puntas de flecha y otras herramientas líticas, algunos fragmentos cerámicos y una espátula de hueso, entre otros.

\subsubsection{Características de la muestra ósea humana}

La muestra recuperada en Los Husos I responde a una inhumación múltiple con algunos materiales con signos de haber sido sometidos a la acción del fuego. En el estrato IIIA lo lógico es pensar en un depósito primario y de naturaleza acumulativa, donde los cuerpos se depositarían en un primer momento en el centro para luego ser reordenados y dispersados. Además, se constatan hogueras (Fig. 6a), de las que han quedado claros rastros en los cuadros D3, E3, F3 y adyacentes, y cuya acción es desconocida en las demás zonas (Apellániz 1974). En cambio, en el estrato IIIB es evidente que la totalidad del área excavada ha sido dedicada a enterramientos. Los únicos rastros de fuego conocidos son unas piedras colocadas irregularmente en los cuadros D3/C3, junto a las que aparecen varios fragmentos informes de cerámica y contados huesos humanos calcinados en contacto con el estrato anterior.

En el nivel IIIA se ha estimado un NMI de 11 a través de porciones esqueléticas postcraneales (un radio, un fémur y varios coxales) para los subdultos y de los coxales para los adultos. Se contabilizaron 7 subadultos (1 infantil I, 1 infantil II y 5 juveniles) según su desarrollo esquelético (Scheuer y Black 2000), y 4 adultos (3 maduros, dos masculinos y uno femenino, y 1 senil masculino) según las características dimórficas de los coxales (Ferembach et al. 1980). En el nivel IIIB se calculó un NMI de 7 a partir de diferentes piezas postcraneales para los subadultos (varios fragmentos de costillas y vértebras y tres cabezas de húmero) y de la región sinfisaria 


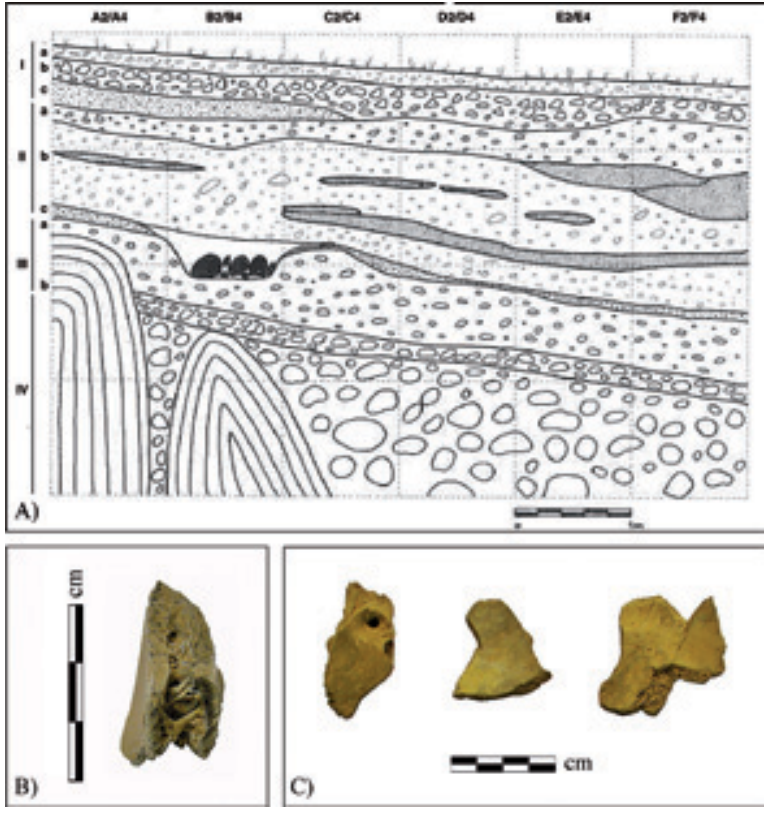

Fig. 6. Los Husos I: A) Corte estratigráfico del depósito arqueológico mostrando los niveles IIIA con el hogar hallado en los cuadros B2/B4 y IIIB (modificado a partir de Apellániz 1974: 40); B) Esquirla con evidencias del denominado efecto "S" o "sándwich" (Reverte 1991), compatible con una quema "en fresco"; C) Fragmentos de cráneo en que solamente la parte interna ha sido afectada por el fuego.

de mandíbula para los adultos. De éstos, 2 eran subadultos (1 infantil I, 1 infantiles II y 2 juveniles) según el desarrollo esquelético (Scheuer y Black 2000), y 3 adultos (2 jóvenes, un varón y una mujer, y 1 maduro femenino) según sus los caracteres de los maxilares inferiores (Ferembach et al. 1980).

\subsubsection{Análisis de las cremaciones}

En torno al 25\% de los cerca de 500 elementos identificables conservados del nivel IIIA de los Husos I están quemados. En cambio, en el nivel IIIB, los tres fragmentos craneales con signos de pirólisis no dejan de ser anecdóticos. Desafortunadamente, los fragmentos óseos no ofrecen buenas cualidades diagnósticas respecto a su quema "en fresco" o "en seco". No muestran patrones claros de alteración ígnea más allá de su coloración, predominantemente negruzca u ocre (y sólo en ocho casos gris-blanquecina), seguramente por su escasa exposición al fuego.

Tan escasa exposición puede deberse a dos mecanismos: una cremación "en seco", seguramente somera y de tipo accidental, que provocaría un ligero chamuscado o "ahumado" propio de quemas entre 300 y $645^{\circ} \mathrm{C}$ (Ubelaker 2007: 57); o una cremación "en fresco" (intencional o no) por debajo de los $800{ }^{\circ} \mathrm{C}$ que ocasionaría una combustión incompleta de la materia orgánica y en que los tejidos blandos evitarían la calcinación de los huesos (Baby 1954: 2).

¿Puede entonces saberse si los fragmentos con signos de fuego hallados en el nivel IIIa mantenían tejidos blandos cuando se quemaron? La respuesta se antoja difícil. Entre todo el material estudiado, sólo se ha localizado una esquirla con claro valor diagnóstico. Es un pequeño fragmento de esqueleto axial que muestra lo que J. M. Reverte (1991: 334) denominó efecto "S" o "efecto sándwich", es decir, zonas carbonosas negras intercaladas entre zonas calcinadas blancas. Esta peculiaridad es propia de una cremación en la que existiría materia orgánica sin combustionar (Etxeberria 1994: 114) (Fig 6b). En cambio, otros fragmentos craneales muestran sólo afectada la zona interna de la bóveda, sugiriendo que ya estuvieran rotos y completamente descarnados cuando se efectuó la quema (Fig. 6c). A este respecto, J. E. Buikstra y M. Swegle (1989) creen posible usar la uniformidad del ahumado para distinguir entre seco y fresco en fragmentos óseos carbonizados. Sin embargo, la importante diversidad de la muestra con ejemplares que vendrían a sumarse a las dos categorías, no permite responder, ni mucho menos, a la pregunta antes planteada. Dada la aparente contradicción entre estos datos debemos recordar que la naturaleza acumulativa $y$, por tanto, dilatada supuesta a este tipo de enterramientos múltiples hace probable que hubiese huesos desecados y otros que no lo estuvieran.

J. M. Apellániz interpretaba el fuego como resultado de una cremación ritual dado que los hogares identificados en el nivel no cubrían toda la superficie funeraria, aglutinándose, para mayor dificultad interpretativa, en el contacto con la zona no excavada de la cueva (cuadros D3, E3, F3 y adyacentes). Su actividad se habría dado de manera "organizada (...), con los hogares y fuegos en un mismo lugar durante mucho tiempo" (Apellániz 1974: 134). En nuestra opinión, nin- 
guna de estas evidencias basta para justificar una cremación ritual. La leve y marginal afectación que presentan casi todos los fragmentos, fueran quemados "en seco" o no, apoyaría una quema accidental, limitada a los huesos en contacto con las hogueras. La presencia de huesos quemados fuera del área de hogares es explicable por la dispersión posterior de los restos, muy aceptable si se considera el estado de remoción de todo el nivel. No es imposible que "las hogueras, restos de cremación y dispersión de huesos pudieran ser resultado de un deseo de acondicionar el lugar para ser habitada nuevamente, desplazando e incluso intentando quemar los restos pertenecientes a la anterior etapa" (Andrés 1979: 19). No en vano, no hay vestigios de realimentación funeraria en los niveles posteriores y los hogares mencionados se localizan en la parte superior del nivel, al cual curiosamente se superpone un nivel de habitaciónredil (IIc) en que sobresale la presencia de hogares (Apellániz 1974: 67).

\subsection{Los Husos II (Elvillar, Álava)}

\subsubsection{Presentación del sitio}

J. M. Apellániz (1974) descubrió el abrigo de Los Husos II durante sus excavaciones en el vecino abrigo de Los Husos I. J. Fernández Eraso (2007/2008) realizó un sondeo en 2001, dirigiendo sucesivas campañas de excavación entre 2003 y 2006. Como resultado, se registró una estratigrafía definida por una decena de niveles arqueológicos. El uso funerario queda limitado al nivel III, un pequeño dispositivo en forma de hoyo cilíndrico de base cóncava, situado en la zona suroeste del cuadro $\mathrm{C} 1$. Mide en la boca 47 por $38 \mathrm{~cm}$ y su profundidad es de $61 \mathrm{~cm}$. Se muestra como una intrusión en la masa del nivel IV que conforma el único testimonio claro de uso del depósito en época calcolítica, quizá por arrasamiento del resto del mismo por las gentes tardoantiguas (Fig. 7a, 7b).
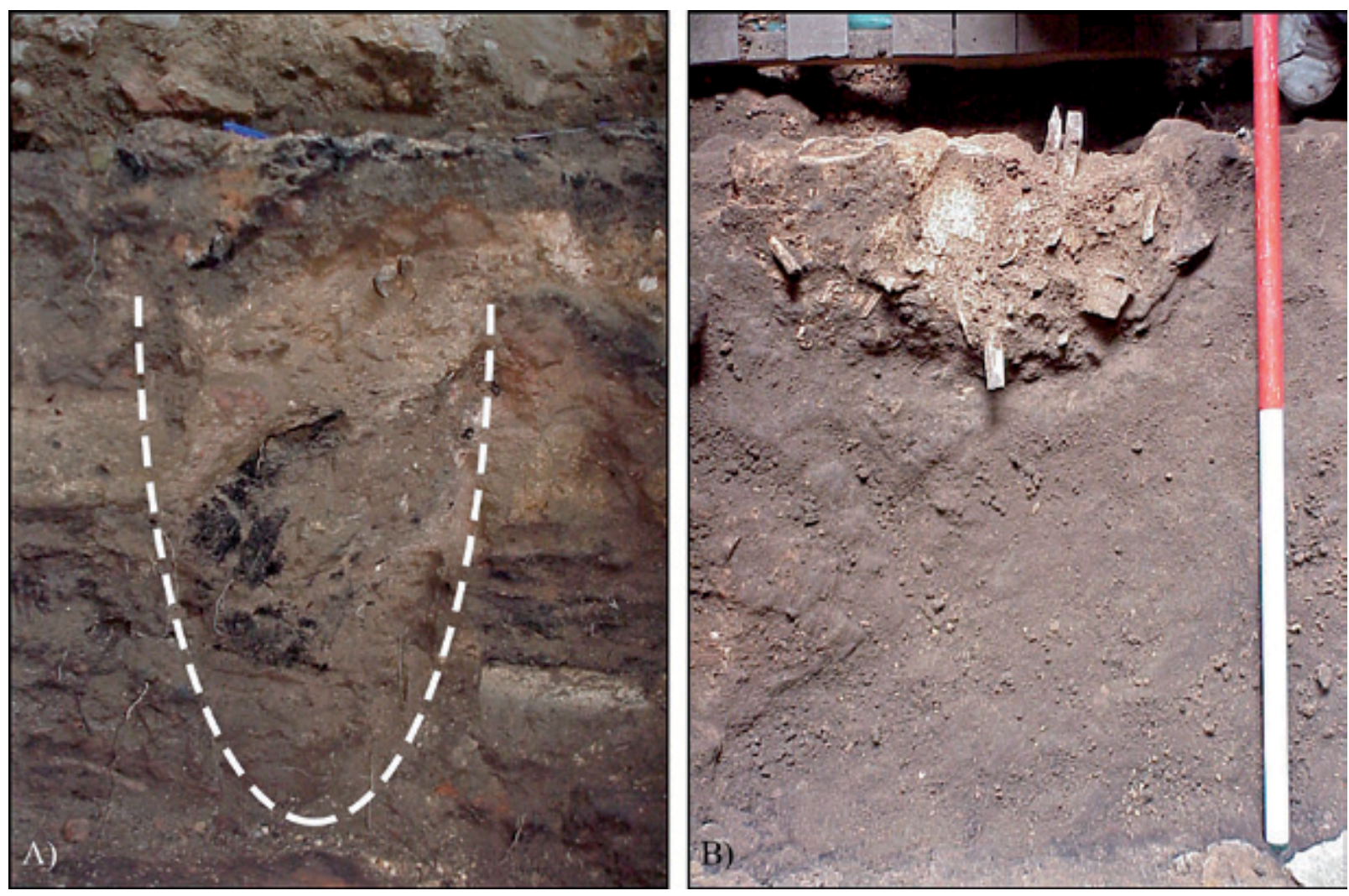

Fig. 7. Los Husos II: A) La sección muestra la potencia y forma del hoyo funerario; B) Parte superior del mismo hoyo visto en planta (fotografías cedidas por J. Fernández Eraso, tomadas el 25-VII-2004).

Trab. Prehist., 73, N. ${ }^{\circ}$ 1, enero-junio 2016, pp. 128-146, ISSN: 0082-5638 doi: $10.3989 /$ tp.2016.12167 
En su interior se recuperaron abundantes huesos humanos totalmente calcinados pertenecientes a cerca de 20 individuos, entremezclados con fragmentos de sílex, una concha de Trivia sp. perforada a modo de colgante y una espátula de hueso.

Durante la campaña de 2003 se recogieron varias muestras en el nivel III, que fueron remitidas al laboratorio Beta Analytic Inc. de Miami (EE. UU.) para su análisis mediante C14. La única fechable (carbón), ofreció una datación de 4670 \pm 50 BP (3631-3357 cal. BC, 20; Beta-208847) (Fernández Eraso 2006: 49).

\subsubsection{Características de la muestra ósea humana}

La muestra de Los Husos II responde a una cremación múltiple recogida en un hoyo localizado en un abrigo bajo roca: un dispositivo excepcional en el Calcolítico peninsular y con escasos referentes de cierta similitud a escala europea (Blaizot et al. 2001).

El estado de conservación de los restos óseos era muy deficiente, por un elevado índice de fragmentación seguramente provocado por la alta incidencia del fuego en la práctica totalidad de los mismos: con un 92\% aproximadamente con coloraciones blancas y grisáceas y con el $8 \%$ restante también quemado pero con tonalidades negruzcas u ocres. Siguiendo las directrices de $\mathrm{H}$. Duday, G. Depierre y T. Janin (2000) para facilitar el cálculo del NMI, se procedió al cómputo de las casi 6.000 evidencias óseas localizadas, en su mayoría fragmentarias, y a su agrupación por regiones anatómicas. Se estableció un NMI de 18 sujetos, a partir de diversos fragmentos de fémures, isquiones y maxilares para los subadultos y de la región sinfisaria de la mandíbula para los adultos. De éstos 11 eran subadultos (1 feto, 7 infantiles I, 1infantil II y 2 juveniles) (Scheuer y Black 2000) y 7 adultos de edad indeterminada (5 mujeres y 2 hombres) (Ferembach et al. 1980).

\subsubsection{Análisis de las cremaciones}

El examen del material antropológico ha puesto de manifiesto, como ya anunciábamos, la calcinación de la mayoría de los restos óseos recu- perados en el dispositivo en hoyo de Los Husos II. El color blanco viejo -denominado altweiss (Wahl 1981) - que evidencia cerca del 95\% de los casi 2.000 restos identificables se relacionaría con temperaturas superiores a $650^{\circ} \mathrm{C}$ (Bonucchi y Graziani 1975; Wahl 1981; Susini et al. 1988; Mays 1998), $750{ }^{\circ} \mathrm{C}$ (Holck, 1986; Hummel et al. 1988) o $950{ }^{\circ} \mathrm{C}$ (Shipman et al. 1984), dependiendo de los autores consultados. Ello abogaría por una combustión muy intensa. El resto, algunos fragmentos de costillas y vértebras, varias falanges, un navicular, tres dientes y dos huesos largos infantiles procedentes de los cuadros C3, C5 y B3 entre las cotas -205 y $-230 \mathrm{~cm}$, mostraba unas coloraciones negras o tendentes a marrón, típicas de temperaturas bajas, quizá por su lejanía del foco del fuego. Dado que los trabajos de campo constataron la secuencia aparentemente no alterada del hoyo, habría que dar por hecho que allí se realizó la quema utilizando un combustible vegetal (de taxón aún sin especificar) del que se conservan grandes masas carbonosas.

Se ha comprobado que una parte muy significativa de la colección (pues no todos los restos muestran las mismas cualidades diagnósticas) exhibe patrones de alteración morfológica compatibles con una cremación "en fresco": a) fracturas de tendencia curvilínea o concéntrica de morfología irregular y estrías en forma de uña o recorte de pulgar, laguna desecada y arañazos de gato (Reverte 1990: 334); b) reducción de algunas porciones óseas (Herrmann et al. 1990); c) aspecto cristalino y friable (Etxeberria 1994: 114); d) sonido característico (Botella et al. 2000: 147); e) retorcimiento de estructuras (Baby 1954; Binford 1963; Thurman y Willmore 1981); f) deformidades en las zonas de menor resistencia del hueso (loci minoris resistentiae) con la forma y dirección esperadas, especialmente destacadas a lo largo de los bordes fracturados en los huesos largos y en los fragmentos de calota, abarquillados y torsionados por el calor (Reverte 1991); g) ejemplos de fragmentos con zonas carbonosas negras intercaladas entre zonas calcinadas blancas ("efecto sándwich"), especialmente en el diploe, y multitud de piezas dentarias que han perdido la corona por estallido de la cavidad pulpar a nivel del cuello, quedando sólo las raíces dentro de sus alvéolos en los maxilares y mandíbulas (y conservándose las coronas de forma muy anecdótica) (Reverte 1990: 334) (Fig. 8).

Trab. Prehist., 73, N. ${ }^{\circ}$ 1, enero-junio 2016, pp. 128-146, ISSN: 0082-5638

doi: $10.3989 /$ tp.2016.12167 


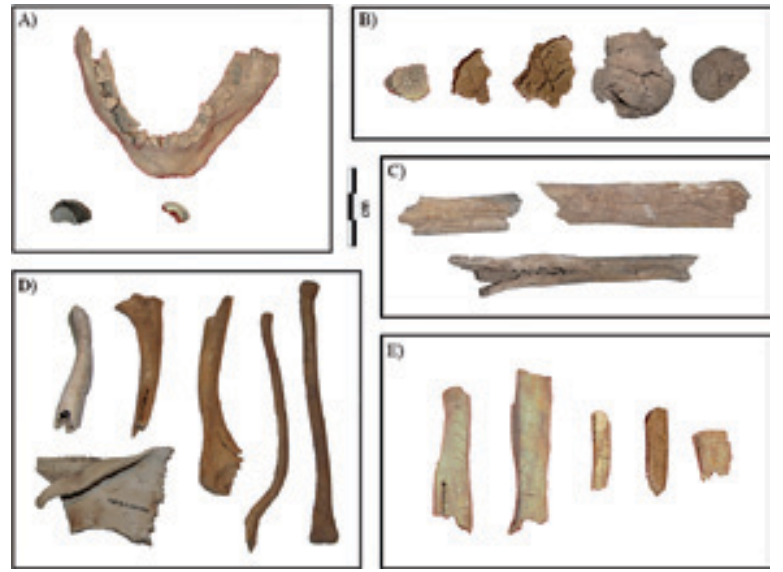

Fig. 8. Restos óseos de Los Husos II con evidencias que apuntan a una quema "en fresco": A) fracturas longitudinales y deformaciones en las zonas de menor resistencia de los huesos largos; B) grietas en forma de laguna desecada y arañazos de gato en regiones cóncavas y convexas; C) "efecto sándwich"; D) deformidad notoria y reducción de huesos planos y largos; E) estrías transversales en forma de uña en huesos largos.

La mayoría de los autores parecen relacionar los patrones enumerados con una cremación lenta en que tras la afectación inicial de los tejidos blandos, el hueso quedaría expuesto y comenzaría a sufrir cambios en su estructura y composición. Finalmente el componente mineral superviviente soportaría diversos procesos de contracción y deformación (Mays 1998; Trancho 2010).

No obstante, el tamaño francamente pequeño y la morfología bastante profunda y no especialmente ancha del hoyo de Los Husos II, donde según los trabajos de campo se habría realizado la quema in situ de los restos (J. Fernández Eraso, com. pers.), son condiciones a priori incompatibles con la introducción de grandes segmentos articulados. Debe presumirse, por tanto, que se encontraran recién descarnados cuando fueron sometidos a la acción del fuego.

No tenemos absoluta certeza, pero creemos bastante posible que los cuerpos se trasladaran completos hasta el abrigo, dada la notable cantidad de piezas menores, huesos cortos y fragmentos costo-vertebrales identificados, poco habituales en los enterramientos secundarios. Allí conformarían un depósito de inhumación múltiple -posiblemente acumulativo-, donde fueron perdiendo sus partes blandas progresivamente. En un momento indeterminado, pero muy posiblemente cercano a su esqueletización, se decidió su quema, para lo cual los restos fueron introducidos en un hoyo estrecho y profundo. Dada la composición del hoyo (multitud de huesos de pequeñas dimensiones, algunos restos de fauna doméstica y salvaje también quemada, tierra, piedrecillas, restos de carbón y algunas piezas de ajuar) y el aparente tímido buzamiento de la secuencia, parece más adecuado pensar en un barrido hacia el hoyo con una pala o herramienta similar que en una recogida selectiva (pick-up).

Resulta difícil explicar esta práctica. De deberse a un comportamiento ritual, cabe preguntarse por qué se esperó para cremar los cuerpos a tener tal concentración de individuos (presumiblemente, en desigual proceso de descomposición) en vez de quemar cada cadáver al depositarlo. Tampoco parece probable que el fuego tuviera una finalidad sanitaria como medida de erradicación de ciertas enfermedades epidémicas (Zammit 1991: 72). De ser así, tendríamos que pensar en una epidemia no selectiva, un depósito prácticamente simultáneo y una quema "en fresco" de todo el material, lo que a priori no se amolda a lo documentado.

También ofrece dudas relacionar la quema con un deseo de acondicionar el lugar para un nuevo uso por gentes de cronología diferente a las que realizaron el enterramiento (aunque del mismo episodio cultural). Esta hipótesis planteada por J. Fernández Eraso (2007/2008: 681), elocuente en abrigos cercanos como Los Husos I y Peña Larga, donde enterradores y cremadores bien pudieron ser grupos cronológicamente distintos, no parece ajustarse tan bien a los datos antropológicos de Los Husos II. Recordemos que el patrón de alteración térmica observado durante nuestro estudio vincula el grueso de la colección con una afectación cuando los restos conservaban tejidos blandos o acababan de esqueletizarse, lo que no parece posible transcurridas varias décadas.

En nuestra opinión y asumiendo que las gentes que realizaron la quema fueron si no las mismas, absolutamente contemporáneas a las que llevaron a cabo el supuesto depósito de los cadáveres, podemos plantearnos la cremación como: a) una actividad de acondicionamiento que persiguiera la reducción del volumen del depósito para obtener un espacio libre para nuevas inhumaciones (Guillot y Le Goff 1995: 114) o para sanear el recinto (Andrés 1998: 95 y 122); b) el resultado puntual de un acto punitivo de condenación por parte de 
otra comunidad, o c) una cercenación de la trayectoria funeraria del abrigo nacida en el seno del grupo que lo utilizaba, tal vez por mera necesidad/ practicidad o por abandono del lugar, por ejemplo.

En cualquier caso, todo ello queda ya en el campo de la especulación. El arrasamiento en época romana de la secuencia inmediatamente posterior al uso funerario del hoyo impide observar lo ocurrido en el siguiente episodio, fuera un intento de realimentación funeraria o un uso totalmente diferente al descrito, como el citado en Los Husos I donde se instaló un redil y una zona de habitación con hogares.

Para terminar, ha de referirse la existencia de otros dos hoyos de mayor tamaño no excavados. Presumiblemente coetáneos al estudiado y visibles en el perfil estratigráfico contienen también huesos quemados en una estratigrafía de quema in situ perfectamente ordenada. Un estudio de micromorfología sedimentaria de los mismos ${ }^{1}$ ha puesto de manifiesto la exposición de los huesos a la intemperie durante un tiempo indeterminado antes de su cremación dado que, en el momento de la quema, los restos óseos portaban bacterias que también se vieron afectadas por el fuego. También se ha constatado el inmediato ocultamiento de los dispositivos con tierra, una vez los huesos fueron sometidos a la acción del fuego. Así las cosas, se antoja posible que la práctica de introducir los huesos en hoyos, quemarlos y cubrirlos con sedimento respondiera a la voluntad de utilizar el abrigo con otra función distinta a la que se le presumía y cercenar por tanto su trayectoria funeraria.

\subsection{Peña Larga (Cripán, Álava)}

\subsubsection{Presentación del sitio}

El abrigo de Peña Larga se sitúa en la vertiente sur de la Sierra de Cantabria, al resguardo de un estrecho espolón calizo. Descubierto en 1984, J. Fernández Eraso (1997: 28-29) dirigió la excavación que comenzó al año siguiente y se prolongó

\footnotetext{
${ }^{1}$ Fernández-Crespo, T. 2012: Antropología y prácticas funerarias en las poblaciones neoliticas finales y calcoliticas de la región natural de La Rioja. Tesis Doctoral inédita. Universidad del País Vasco. Vitoria.
}

durante cuatro campañas. La estratigrafía puso de manifiesto varios niveles arqueológicos de cronología prehistórica. El uso funerario del depósito se limitaba al nivel III, donde se depositaron al menos 30 individuos junto con diversos fragmentos cerámicos, tres puntas de pedúnculo y aletas y varios punzones óseos. El nivel proporcionó las fechas

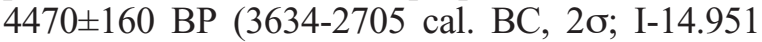

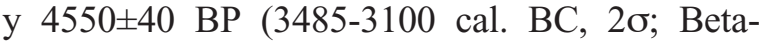
299948), obtenidas sobre hueso humano y animal respectivamente (Fernández Eraso 1997; Fernández Eraso y Mujika 2013; Rofes et al. 2013).

\subsubsection{Características de la muestra ósea humana}

La muestra de Peña Larga responde, muy posiblemente, a un enterramiento múltiple acumulativo en abrigo en que casi la mitad del conjunto óseo humano presenta signos de alteración térmica (Fig. 9a). El conjunto óseo está revuelto, como es habitual en este tipo de dispositivos. No
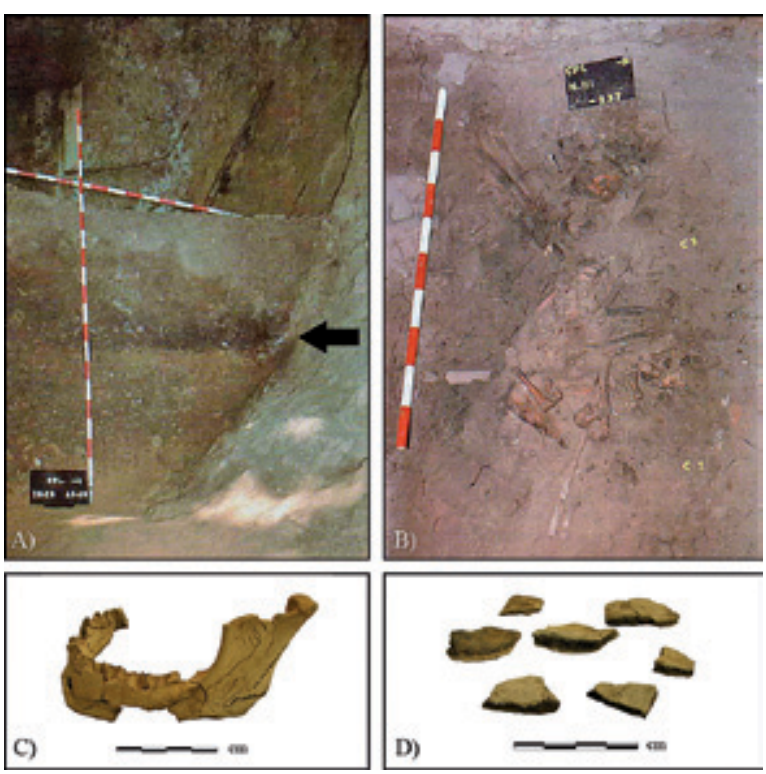

Fig. 9. Peña Larga: A) corte estratigráfico donde se aprecia el nivel funerario o III de color negro por la abundancia de carbones y restos humanos quemados (modificado a partir de Fernández Eraso 1997: 44); B) vista en planta de uno de los esqueletos en conexión del nivel III (modificado a partir de Fernández Eraso 1997: 44); C) mandíbula con deformación y estrías compatibles con una quema "en fresco"; D) fragmentos de hueso plano con "efecto sándwich". 
obstante, "en los cuadros C-1 y C-2, los más próximos a la pared Norte y dentro de la especie de hornacina semicircular que forma la pared del abrigo, se localizaron dos esqueletos completos en conexión anatómica (Fig. 9b). En otros cuadros, A-3, B-1, aparecen, tan sólo, extremidades en conexión anatómica pero nunca formando parte de un esqueleto completo" (Fernández Eraso 1997: 42).

El NMI de 30 individuos se estimó recontando restos mandibulares y postcraneales para los subadultos y las mandíbulas, en concreto la región del tercer molar izquierdo (aunque las sínfisis también ofrecieron una muy buena representación), para los adultos. De éstos, 12 eran subadultos (7 infantiles I, 2 infantiles II y 2 juveniles), según el desarrollo dental y esquelético (Ubelaker 1989; Scheuer y Black 2000) y 18 adultos en su mayoría de edad indeterminada ( 7 femeninos, 3 masculinos y 8 de sexo indeterminado) (Ferembach et al. 1980).

\subsubsection{Análisis de las cremaciones}

El análisis de las alteraciones térmicas ha identificado algunos ejemplares con signos de contracción, deformidad o agrietamiento. Otros fragmentos, generalmente de diploe, blancos en la cortical y con coloraciones azuladas en el interior permiten vincular una pequeña parte del material con una cremación posiblemente "en fresco" (Fig. 9c, 9d). Las piezas más afectadas se localizan en los cuadros A1, B1, B2 y C1 y C2 (con profundidades entre $-230 \mathrm{y}-245 \mathrm{~cm}$ ), que reúnen casi el total de los fragmentos con coloraciones blancas (excepciones en C3 y Z2).

Las coloraciones de los demás restos afectados por el fuego ( $45 \%$ de los más de 7.000 elementos óseos identificables) son en general marrones o negras. No evidencian contracción ni reducción de peso frente al efecto calorífero, o lo hacen mucho menos. Además, no muestran deformidades apreciables y su intensidad de fragmentación es sensiblemente más reducida, exhibiendo patrones de fractura normalmente paralelo/transversales al eje mayor de los huesos largos: características típicas de una quema "en seco".
Se aboga, por tanto, por una quema prioritariamente efectuada sobre material antropológico seco y en parte cubierto ya por sedimento. No en vano, en el tramo más superficial del nivel III se localizaron abundantes huesos "bien carbonizados, bien totalmente calcinados", mientras que bajo él sólo estaban "carbonizadas las partes más sobresalientes o elevadas" de los huesos (Fernández Eraso 1997: 41-42). Lo difícil es explicar que haya piezas cuyo patrón de afectación ígnea es compatible con una cremación cuando los sujetos aún conservaban tejidos blandos.

Parece probable que, en cierto momento de la historia del lugar, los huesos, previsiblemente descarnados (según los resultados antropológicos) y ya medio ocultos por el sedimento aportado, se cubrieran con ramas de avellano y encina, como sugiere el hallazgo de carbones atribuidos a dichos taxones y de cáscaras carbonizadas de avellana en la capa superior del nivel (Fernández Eraso 1997; Pérez Díaz et al. 2010). Tras prenderles fuego, y con la superficie aún candente, se les revestiría con una capa de piedras (Fernández Eraso 1997: 174). Resulta curioso que los esqueletos articulados (muy posiblemente, de los últimos inhumados en el lugar) apenas se vean afectados por el fuego, quizá por resguardarlos la especie de hornacina pétrea en que se hallaban.

Esta operación es atribuible a gentes del mismo periodo cultural dada la presencia de algunos restos quemados posiblemente "en fresco" y la inmediata cronología atribuida al nivel posterior. Ello nos lleva a relacionar el uso del fuego en este dispositivo "con una mera cuestión de higiene" o clausura del depósito funerario motivada por una "reutilización del lugar con fines opuestos al uso anterior", concretamente como refugio temporal en el nivel II (Fernández Eraso 2007/2008: 681).

La decisión de ocupar un yacimiento funerario con otra finalidad "nos cuestiona sobre la naturaleza sacra de los lugares de enterramiento" (Fernández Eraso 2007/2008: 681). Sin embargo la propia forma de clausura de su trayectoria (cremación), a menudo tildada de gestión purificadora, y la construcción de un empedrado crean una frontera definida entre ambos usos que bien podría estar indicándonos no sólo un protocolo higiénico sino cierta deferencia o consideración con respecto al primero. 


\subsection{La Peña de Marañón (Marañón, Navarra)}

\subsubsection{Presentación del sitio}

El abrigo de La Peña de Marañón se localiza en el barranco de Roñes dominando el curso del río Ega, en las estribaciones nororientales de la Sierra de Cantabria. Fue descubierto casualmente debido a una extracción de gravas en la zona y excavado de urgencia en 1983, dada la inestabilidad del sedimento, durante dos campañas bajo la dirección de A. Cava y M. A. Beguiristain (1991/1992), identificándose una ocupación entre el Mesolítico y la Edad del Hierro. El nivel c, correspondiente culturalmente al Neolítico o más probablemente a inicios del Calcolítico (las muestras enviadas a datar no tenían colágeno), fue el único funerario identificado en la secuencia. La zona más arrinconada y protegida del abrigo (Fig. 10) se escogió para depositar unos 30 individuos. Sus restos mostraban alteraciones por remoción -sobre todo una intensa fragmentación- y claros signos de cremación, junto con un escaso ajuar en que destaca una punta de flecha foliácea y contados adornos personales en concha y piedra.

\subsubsection{Características de la muestra ósea humana}

El rito realizado en el interior de este abrigo fue muy posiblemente la inhumación múltiple acumulativa. La representación de todas las porciones anatómicas confirma la naturaleza primaria del depósito. El estado de fragmentación y de cremación parcial de los restos sugiere un depósito escalonado de los cadáveres, donde la introducción sucesiva de los individuos remueve en profundidad los anteriores (Cava y Beguiritain 1991/1992: 126).

El NMI de La Peña se ha estimado mediante el recuento de las porciones mandibulares, salvo para un individuo subadulto identificado por otras piezas postcraneales. Se contabilizaron 12 subadultos (6 infantiles I, 2 infantiles II y 4 juveniles) (Scheuer y Black 2000; Ubelaker 1989). La cifra de 16 sujetos adultos (10 femeninos, 1 masculino y 5 de sexo indeterminado) (Ferem-
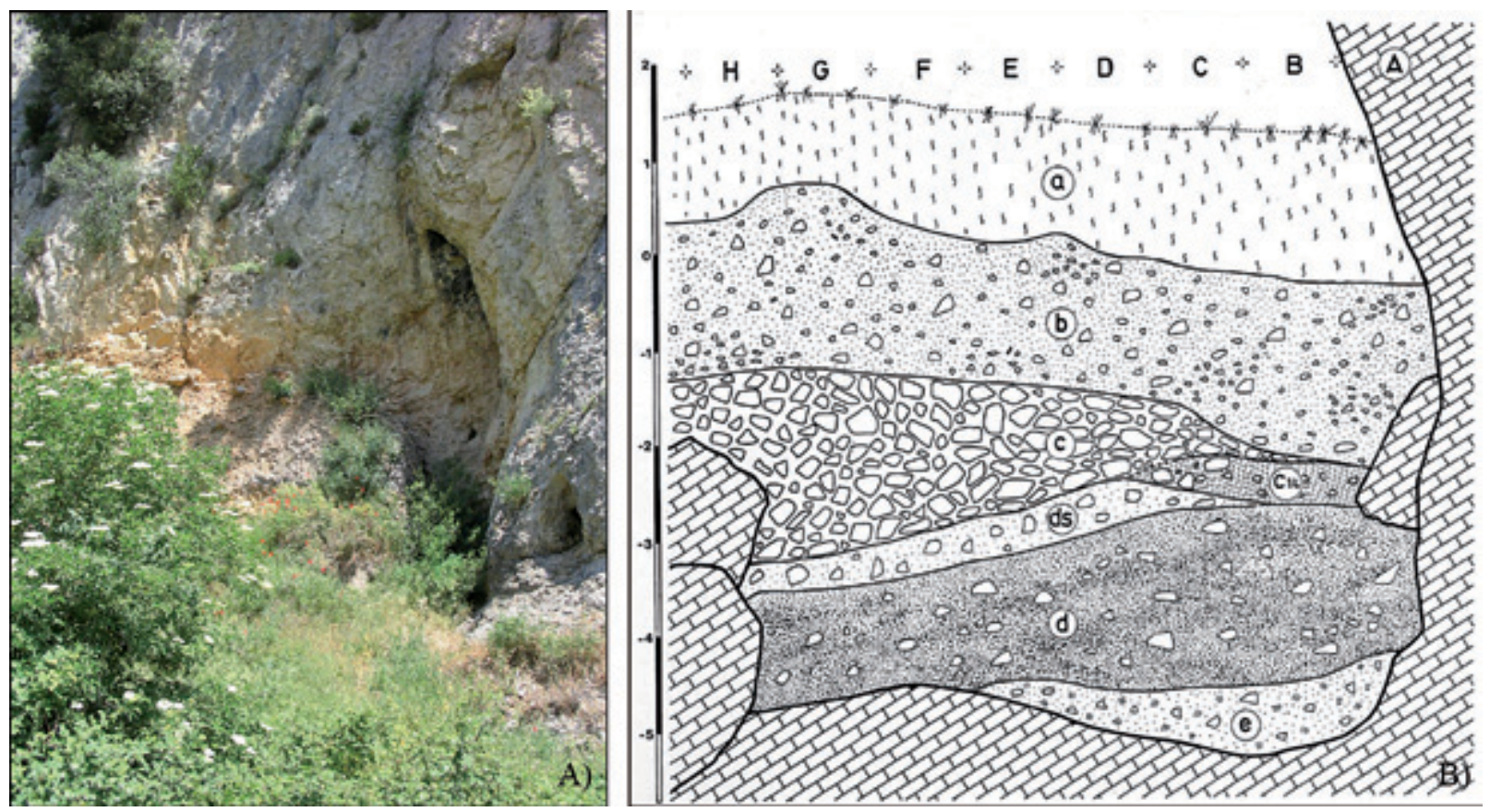

Fig. 10. La Peña de Marañón: A) vista del abrigo en la actualidad desde el sur; B) corte estratigráfico del depósito indicando la posición del nivel funerario (c1/4) al fondo del abrigo (modificado a partir de Cava y Beguiristain 1991/1992: 128).

Trab. Prehist., 73, N. ${ }^{\circ}$ 1, enero-junio 2016, pp. 128-146, ISSN: 0082-5638

doi: $10.3989 /$ tp.2016.12167 
bach et al. 1980) se calculó a partir de la región del primer molar derecho.

\subsubsection{Análisis de las cremaciones}

Ya el primer análisis antropológico realizado en La Peña de Marañón indicaba que "buena parte de la colección había sido afectada por el fuego que la deforma y altera" (Basabe 1991/1992: 165). El presente, además de corroborar tal manipulación en cerca del $80 \%$ de los más de 4.000 restos humanos identificables estudiados, evidencia la quema "en fresco", es decir, conservando tejidos blandos o recién esqueletizados, de una parte importante de la colección. Éstos proceden en su mayoría de la última capa (c1) del nivel funerario y son huesos "de aspecto blanquecino, profundamente alterados en su forma y composición habiendo perdido parte de su peso y produciendo a la percusión un sonido casi metálico" (Cava y Beguiristain 1991/1992: 127).

Abundan en este nivel huesos largos con llamativas deformidades y grandes grietas, longitudinales y transversales en las diáfisis y de tendencia concéntrica en las epífisis y otras zonas cóncavas, así como fragmentos de bóveda craneal “abarquillados por el calor” (Basabe 1991/1992: 165). Estos rasgos son típicos en huesos quemados poco después del deceso con o sin tejidos blandos conservados. Tampoco son raras las piezas con zonas carbonosas negras y calcinadas blancas intercaladas entre si, que ciertos autores denominan "efecto sándwich". Comúnmente se relaciona con "una cremación en la que existiría materia orgánica sin combustionar" (Etxeberria 1994: 114) (Fig. 11), lo que sugiere una relativa cercanía temporal entre la deposición de los últimos cadáveres y su cremación.

Durante el análisis antropológico se localizaron conexiones anatómicas entre piezas procedentes de los mismos contextos estratigráficos, las denominadas liaisons de deuxième ordre por la Anthropologie de terrain. Los casos más claros son los de una mandíbula, una escápula, un húmero, un cúbito y un radio izquierdos pertenecientes a un sujeto perinatal; una clavícula, un cúbito y un radio derechos de un individuo de 2 años de edad; y sendos coxales de un mismo subadulto. Creemos muy posible que muchos de los restos

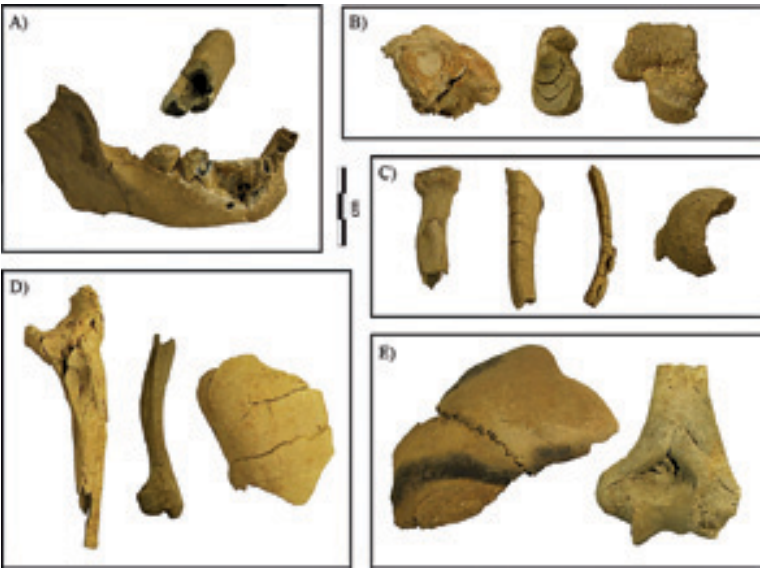

Fig. 11. Huesos de La Peña de Marañón con señales de haber sido sometidos al fuego "en fresco": A) "efecto sándwich" en huesos largos y piezas dentarias; B) grietas concéntricas y en forma de laguna desecada o arañazo de gato en regiones cóncavas y convexas; C) estrías en forma de uña y fracturas serradas en huesos largos; D) deformación de huesos largos y planos; E) coloración variable de huesos dependiendo del contacto con el fuego.

se hallaran aún conectados o en proceso de descomposición en el momento de la quema.

Parece bastante plausible, como interpretación de los signos de alteración térmica, que "las cremaciones parciales que afectan en distinto grado y aspecto a los huesos pueden ser fruto de labores de higienización periódica del covacho entre unos enterramientos y otros (...); o al final de todo el proceso de enterramientos por parte del grupo humano que se estableció sobre ellos para iniciar una nueva etapa de habitación" (Cava y Beguiristain 1991/1992: 127). No en vano los huesos de c1 son precisamente los más afectados por el fuego y, quizá con contados ejemplares procedentes de zonas altas de c2, los únicos de la serie que parecen haber sido quemados cuando aún conservaban parte de sus tejidos blandos o se encontraban recién descarnados.

\section{DISCUSIÓN}

El papel del fuego en las cavidades sepulcrales no ha sido suficientemente debatido pese a ser una evidencia relativamente repetida como se denunciaba en la "Reunión Internacional sobre el significado del fuego en los rituales funerarios del 
Neolítico" celebrada en Medinaceli en 1999 (Rojo y Kunst 2002). El carácter abierto de cuevas y abrigos y sus habituales largas secuencias de utilización propician la atribución de los restos con signos de alteración térmica a causas accidentales producidas en momentos posteriores al de su uso como depósitos funerarios, especialmente cuando los huesos quemados son escasos y sobre todo si se hayan en el estrato más superficial o sobre el sedimento. En general se entienden como producto de actividades propias de la Edad del Hierro o resultado de fogatas de pastores.

En su revisión del material óseo procedente de algunas cavidades funerarias vascas, a partir de las cuales la literatura arqueológica tradicional mantenía la convivencia del ritual inhumatorio con el de cremación aunque en diferente proporción, A. Armendáriz ${ }^{2}$ halló un fenómeno bastante dudoso, o al menos, menos frecuente de lo que se había supuesto. Por ejemplo, en Las Pajucas, Getaleuta, Txotxinkoba y Kobeaga I no se observaban huesos quemados, aunque los había ennegrecidos de un modo natural, lo que había podido llevar a confusión. En Gerrandijo y Aldeacueva los había tanto humanos como animales pero en pequeña cantidad. En Los Zorros había abundantes, pero lo más probable era que fueran resultado de su uso prolongado como refugio en épocas recientes. En Arratiandi bastantes huesos presentaba signos de cremación, pero también parte del ajuar, lo que según los autores resultaba raro. Además, el yacimiento, o buena parte de él, se hallaba revuelto en época reciente, lo que podía hacer dudar de la ritualidad de las mencionadas cremaciones. En Gobaederra la incineración parecía deberse a la acción de una hoguera, ya que solo 34 del total de 4.899 huesos tenían signos de cremación.

Otros ejemplos, también en el País Vasco, tienen un escaso número de huesos cremados, cuya quema en general se atribuye a causas fortuitas: Lacilla, Txispiri, Marizulo, Lamikela, Pico Ramos y Ozakar ${ }^{3}$.

Salvo excepciones, la información disponible es bastante inespecífica. Como bien se ha seña-

\footnotetext{
2 Polo, A. 2010: Rediles prehistóricos y uso del espacio en abrigos bajo roca en la Cuenca Alta del Ebro: geoarqueología y procesos de formación durante el Holoceno. Tesis Doctoral inédita. Universidad del País Vasco. Vitoria-Gasteiz.

3 Armendáriz Gutiérrez, A. 1992: Las cuevas sepulcrales del País Vasco. Tesis doctoral inédita. Universidad del País Vasco. Vitoria-Gasteiz. Véanse pp. 690-712.
}

lado no distingue "entre las posibles alteraciones térmicas sufridas por el material (p. e. calcinación, combustión), el número de individuos afectados, el tipo de hueso afectado y su frecuencia, el nivel de articulación que presentaba la pieza al momento de ser expuesta al fuego o la brasa, entre otras características" (Baraybar y de la Rúa 1995: 167).

No obstante, el presente estudio ha demostrado que estas señales de fuego en depósitos funerarios en cuevas del Neolítico final/Calcolítico inicial, además de no ser inhabituales, tienen cierta entidad en el caso de las de la Sierra de Cantabria y su entorno, como ya se había documentado en otras regiones del noreste (Agustí 2002), el centro (Gutiérrez et al. 2002) y el sudeste (Idáñez 1984) de la península ibérica.

A partir de distintos protocolos surgidos de la experimentación forense, se ha establecido la quema "en seco" y, probablemente accidental, de los restos humanos procedente de los abrigos de Las Yurdinas II y Los Husos I y, tal vez, de Peña Larga (con algunas piezas dudosas, cuyos signos podrían ser compatibles con una quema "en fresco"). El número de piezas con signos de actividad ígnea, salvo en Peña Larga, es bajo. Presentan un color negruzco (propio de un ligero chamuscado) con fisuras y grietas profundas y longitudinales, craquelados superficiales y sin deformaciones estructurales (Tab. 1).

En cambio, en Los Husos II y La Peña de Marañón, el mecanismo parece ser diferente. La práctica totalidad de los restos de ambos depósitos muestra una coloración mayoritariamente blanquecina o grisácea, y está profundamente alterada en su forma y composición, generando llamativas deformidades y fracturas transversales y de tendencia curvilínea, habiendo perdido parte de su peso y produciendo a la percusión un sonido casi metálico. Ello, unido a la presencia de zonas oscuras intercaladas entre superficies blanquecinas, invita a pensar en una cremación "en fresco" sobre huesos recientemente descarnados o incluso en proceso de pérdida de sus partes blandas. En ninguno de los dos sitios se identificaron conexiones anatómicas claras que avalen una cremación de cadáveres completos, sino piezas y fragmentos desordenados propios de un fenómeno funerario acumulativo y de larga data. Se sugiere así relacionar los testimonios de fuego en ambos casos con una manipulación postdeposicional puntual del uso funerario del

Trab. Prehist., 73, N. ${ }^{\circ}$ 1, enero-junio 2016, pp. 128-146, ISSN: 0082-5638

doi: $10.3989 /$ tp.2016.12167 


\begin{tabular}{|c|c|c|c|c|c|c|c|c|}
\hline \multirow[b]{2}{*}{ Sitio } & \multirow[b]{2}{*}{ NMI } & \multirow[b]{2}{*}{ NR } & \multirow[b]{2}{*}{ NRI } & \multirow{2}{*}{$\begin{array}{c}\% \text { NRI } \\
\text { afectado } \\
\text { por el } \\
\text { fuego }\end{array}$} & \multicolumn{4}{|c|}{ Alteraciones relacionadas con el fuego } \\
\hline & & & & & $\begin{array}{c}\text { Color } \\
\text { dominante }\end{array}$ & $\begin{array}{l}\text { Aspecto } \\
\text { general }\end{array}$ & $\begin{array}{l}\text { Deformación } \\
\text { o torsión }\end{array}$ & $\begin{array}{l}\text { Patrón } \\
\text { de fractura }\end{array}$ \\
\hline $\begin{array}{c}\text { Las Yurdinas } \\
\text { II }\end{array}$ & 90 & 58.761 & 39.102 & $20 \%$ & $\begin{array}{l}\text { Marrón- } \\
\text { negro }\end{array}$ & Pulverulento & Ausente & $\begin{array}{l}\text { Paralelo- } \\
\text { transversal }\end{array}$ \\
\hline Los Husos I & 18 & 557 & 519 & $25 \%$ & Ocre-negro & Pulverulento & Ausente & $\begin{array}{l}\text { Paralelo- } \\
\text { transversal }\end{array}$ \\
\hline Los Husos II & 18 & 5.986 & 1.838 & $92 \%$ & Blanco-gris & Liso y vítreo & Presente & $\begin{array}{c}\text { Curvilíneo, } \\
\text { concéntrico, } \\
\text { irregular }\end{array}$ \\
\hline Peña Larga & 30 & 29.896 & 7.299 & $45 \%$ & $\begin{array}{l}\text { Marrón- } \\
\text { negro }\end{array}$ & Pulverulento & Ausente & $\begin{array}{l}\text { Paralelo- } \\
\text { transversal }\end{array}$ \\
\hline $\begin{array}{l}\text { La Peña de } \\
\text { Marañón }\end{array}$ & 28 & 13.835 & 4.135 & $80 \%$ & Blanco-gris & Liso y vítreo & Presente & $\begin{array}{c}\text { Curvilíneo, } \\
\text { concéntrico, } \\
\text { irregular }\end{array}$ \\
\hline
\end{tabular}

Tab. 1. Principales alteraciones relacionadas con el fuego documentadas en los restos óseos de las colecciones estudiadas. NMI = Número Mínimo de Individuos; NR = Número total de Restos estudiados; NRI = Número total de Restos Identificables estudiados.

abrigo y no con un tratamiento en sí mismo, entendiendo éste como un rito realizado durante el depósito de los sujetos.

La motivación de tal práctica no resulta fácil de precisar. Podría tratarse del intento por cercenar la trayectoria secular de ambos sitios, al ser el último episodio funerario documentado en ellos. En Los Husos II es especialmente sugerente el enterramiento de los huesos en un pequeño hoyo para su quema, lo que avala la pérdida de gran parte de los tejidos blandos, y su inmediato ocultamiento posterior con sedimento, según el estudio microsedimentológico de otros hoyos funerarios coetáneos del mismo abrigo (A. Polo, com. pers.). En La Peña de Marañón, donde se detectaron varios finos niveles de cenizas, la cremación puede vincularse a una medida higiénica o práctica. No obstante, el que la última capa funeraria (c1) sea sin duda la más afectada por el fuego podría indicar un mecanismo semejante al propuesto para Los Husos II.

Este recurso al fuego, relacionado con frecuencia con la clausura del nivel funerario de los abrigos bajo roca, puede tener su explicación en factores si no demográficos (movimientos debidos, por ejemplo, a una elevada presión demográfica), al menos ideológicos, plasmados en cambios en el comportamiento funerario (Andrés 2005). Si atendemos a las nuevas formas dolménicas que aparecen en Navarra o al uso de nuevos espacios sepulcrales (pudrideros, casas de muertos, fosas), se percibe que el Neolítico final/Calcolítico inicial en el valle medio del Ebro es un periodo de gran efervescencia poblacional y variabilidad funeraria (Fernández-Crespo 2015).

\section{CONCLUSIÓN}

El estatus aéreo de los depósitos múltiples en abrigos bajo roca ha conllevado durante décadas el menosprecio de los signos de alteración térmica en los restos humanos, atribuyéndoles un origen variopinto y no en pocas ocasiones accidental (actuaciones clandestinas, incendios forestales, usos posteriores,...) que no siempre se corresponde con la realidad. El recurso en la presente investigación a parámetros definidos a partir de la experimentación forense ha permitido proponer una curiosa cercanía temporal entre el depósito y la cremación de los cuerpos o restos en algunas cavidades sepulcrales neolíticas finales/calcolíticas iniciales de la Sierra de Cantabria y sus estribaciones, y desplegar un abanico de posibles interpretaciones. Para Los Husos II y La Peña de Marañón en base a los 
datos del estudio de sus restos, se propone relacionar el uso del fuego con procesos de interrupción o clausura de la trayectoria funeraria vinculados con posibles movimientos poblacionales y/o cambios en el ritual funerario. En cambio para el resto de los abrigos, se aboga por atribuir las señales de fuego a acciones fortuitas o accidentales una vez el depósito funerario deja de utilizarse.

\section{AGRADECIMIENTOS}

A los Dres. Ignacio Barandiarán y Concepción de la Rúa, codirectores de la Tesis Doctoral inédita de la autora, titulada Antropología y prácticas funerarias en las poblaciones neoliticas finales y calcoliticas de la región natural de La Rioja (Universidad del País Vasco, 2012), de la cual deriva en parte este artículo, su asesoramiento y constante apoyo. A los Dres. Javier Fernández Eraso y Ana Cava por facilitar el acceso a las colecciones estudiadas y por las informaciones y materiales inéditos aportados.

Al Ministerio de Educación y Ciencia (HUM2005-04236; HAR2011-26956), al Gobierno Vasco (POS_2013_1_147; POS_2014_2_24; IT542-10) y a la Universidad del País Vasco (UPV/EHU) (UFI 11/09), la financiación que ha permitido desarrollar este trabajo.

\section{BIBLIOGRAFÍA}

Agustí, B. 2002: “Depósitos funerarios con cremación durante el Calcolítico y el Bronce en el Noreste de Catalunya". En M. Rojo y M. Kunst (eds.): Sobre el significado del fuego en los rituales funerarios del Neolítico. Studia Archaeologica 91, Universidad de Valladolid. Valladolid: 65-82.

Andrés, M. T. 1979: "Ritos funerarios de la Cuenca Media del Ebro. Neolítico y Eneolítico". Berceo 97: 3-25.

Andrés, M. T. 1998: Colectivismo funerario neo-eneolítico. Aproximación metodológica sobre datos de la Cuenca Alta y Media del Ebro. Institución Fernando el Católico. Zaragoza.

Andrés, M. T. 2005. Concepto y análisis del cambio cultural: su percepción en la materia funeraria del Neolítico y Eneolítico. Monografías Arqueológicas 42. Dpto de Ciencias de la Antigüedad de la Universidad de Zaragoza, Zaragoza.
Andrés, M. T. 2009: “Comportamiento funerario en el Neolítico y Eneolítico: sociedad e ideología”. En J. Santos (ed.): Los tiempos antiguos en los territorios pirenaicos. Anejos de Veleia, Series acta 8: 11-36.

Apellániz, J. M. 1974: "El Grupo de Los Husos durante la prehistoria con cerámica del País Vasco". Estudios de Arqueología Alavesa 7: 1-409.

Baby, R. 1954: "Hopewell cremation practices". The Ohio Historical Society Papers in Archaeology 1: 1-7.

Baraybar, J. P. y de la Rúa, C. 1995: "Estudio antropológico de la población de Pico Ramos (Muzkiz, Bizkaia)". En L. Zapata (dir.): El depósito sepulcral calcolítico de la cueva Pico Ramos (Muskiz, Bizkaia). Munibe (Antropología-Arqueología) 47: 151-175.

Basabe, J. M. 1991/1992: “Informe antropológico del abrigo de La Peña (Marañón, Navarra)". En A. Cava y M. A. Beguiristain (eds.): El yacimiento prehistórico del abrigo de La Peña (Marañón, Navarra). Trabajos de Arqueología Navarra 10: 165-166.

Binford, L. R. 1963: "An analysis of cremations from three Michigan sites". Wisconsin Archaeology 44 (2): 98-110.

Binford, L. R. 1972: "An analysis of cremations from three Michigan sites". En S. Struevers (ed.): An archaeological perspective. Seminar Press. New York: 373-382.

Blaizot, F.; Böes, X.; Lalaï, D.; Le Meur, N. y Margot, Y. 2001: "Prémières données sur le traitement des corps humains à la transition du Néolithique récent et du Néolithique final dans le Bas-Rhin: dimensions culturelles". Gallia préhistoire 43: 175-235.

Bonucci, E. y Graziani, G. 1975: "Comparative thermogravimetric x-ray diffraction and electron microscope investigations of burnt bones from recent, ancient and prehistoric age". En Atti della Accademia Nazionale dei Lincei. Rendiconti, classe di scienze fisiche, matematiche e naturali 59: 517-532.

Botella, M., Alemán, I. y Jiménez Brobeil, S. A. 2000. Los huesos humanos, manipulaciones y alteraciones. Bellaterra. Barcelona.

Bronk Ramsey, C. 2009: "Bayesian analysis of radiocarbon dates". Radiocarbon 51 (1): 337-360.

Brothwell, D. R. 1965: Digging up bones. The excavation, treatment and study of human skeletal remains. Cornell University Press. Ithaca.

Buikstra, J. E. y Swegle, M. 1989: "Bone modification due to burning: experimental evidence". En R. Bonnichsen y M. H. Sorg (ed.): Bone Modification. Institute for Quaternary Studies, University of Maine. Orono: 247-258.

Cava, A. y Beguiristain, M. A. 1991/1992: "El yacimiento prehistórico del abrigo de La Peña (Marañón, Navarra)". Trabajos de Arqueología Navarra 10: 69-165.

Duday, H.; Courtaud, P.; Crubezy, E.; Sellier, P. y Tillier, A. M. 1990: 'L'Anthropologie de 'terrain': recon-

Trab. Prehist., 73, N. ${ }^{\circ}$ 1, enero-junio 2016, pp. 128-146, ISSN: 0082-5638

doi: $10.3989 /$ tp.2016.12167 
naissance et interprétation des gestes funéraires". Bulletins et Mémoires de la Société d'Anthropologie de Paris 2: 29-50.

Duday, H.; Depierre, G. y Janin, T. 2000: "Validation des paramètres de quantification, protocoles et stratégies dans l'étude anthropologique des sépultures secondaires de incinération. L'exemple des nécropoles protohistoriques du Midi de la France". En Archéologie de la Mort, Archéologie de la tombe au premier Âge du Fer, Actes du XXIe Colloque International de l'Association Française pour l'Étude de l'Âge du Fer (Conques-Montrozier 1997). Monographies d'Archéologie Méditerranéenne 5. Centre National de la Recherche Scientifique. Lattes: 7-29.

Dutour, O.; Berato, L.; Lafont, R. y Perinet, G. 1989: "Analyse de la température de crémation d'incinérations antiques par diffractométrie Rx. Nécropole du Haut Empire de St. Lambert de Fréjus, Var". Revue d'Archéométrie 13: 23-28.

Etxeberria, F. 1994: "Aspectos macroscópicos del hueso sometido al fuego. Revisión de las cremaciones descritas en el País Vasco desde la Arqueología". Munibe (Antropología- Arqueología) 46: 111-116.

Ferembach, D.; Schwidetzky, I. y Stloukal, M. 1980: "Recommendations for age and sex diagnosis of skeletons". Journal of Human Evolution 9: 517-549

Fernández-Crespo, T. 2015: "Aportación de la Arqueoantropología a la interpretación de la dinámica sepulcral de las tumbas megalíticas de Cameros (La Rioja, España)". Trabajos de Prehistoria 72 (2): 218-237.

Fernández-Crespo, T. y de-la-Rúa, C. 2015: "Demographic evidence of selective burial in megalithic graves of northern Spain". Journal of Archaeological Science 53: 604-617.

http://dx.doi.org/10.1016/j.jas.2014.11.015

Fernández Eraso, J. 1997: Peña Larga. Memorias de yacimientos alaveses 4. Diputación Foral de Álava. Vitoria-Gasteiz.

Fernández Eraso, J. 2003: Las Yurdinas II: Un depósito entre finales del IV y comienzos del III milenio BC. Memorias de yacimientos alaveses 8. Diputación Foral de Álava. Vitoria-Gasteiz.

Fernández Eraso, J. 2006: "El abrigo de Los Husos II (Elvillar). III Campaña”. Arkeoikuska 05: 55-50.

Fernández Eraso, J. 2007/2008: "La secuencia del Neolítico en La Rioja Alavesa desde su origen hasta las primeras edades del metal”. En J. Fernández Eraso, J. Santos e I. Barandiarán Maestu (eds.): Homenaje a Ignacio Barandiarán Maestu. Veleia 24-25 (2): 669-688.

Fernández Eraso, J. y Mujika, J. A. 2013: "La estación megalítica de la Rioja Alavesa: Cronología, orígenes y ciclos de utilización”. Zephyrus LXXI: 89-106.

Gejvall, N. G. 1969: "Cremations". En D. R. Brothwell y E. S. Higgs (eds.): Science in Archaeology. Thames \& Hudson. London: 482-493.

Gómez Bellard F. 1996: "El análisis antropológico de las cremaciones". En T. Chapa y M. ${ }^{\text {a A. Querol }}$ (eds.): Homenaje al profesor Manuel FernándezMiranda. Complutum Extra 6, 2: 55-64.

Guillon, F. 1986: "Brulés frais ou brulés secs?". En H. Duday y C. Masset (eds.): Anthropologie physique et archéologie. Méthodes d'étude des sépultures. Actes du colloque de Toulouse (1982): 191-194. Paris.

Guillot, H. y Le Goff, I. 1995: "Les usages du feu". En C. Masset y P. Solier (eds.): Allées couverts et autres monuments funéraires du Néolithique dans la France du Nord-Ouest: allées sans retour. Errance. Paris: 112-114.

Gutiérrez, C. G., Gómez, A. L. y Ocaña, A. O. 2002: "Fuego y ritual en el enterramiento colectivo de Cueva Maturra (Argamasilla de Alba, Ciudad Real)". En M. Rojo y M. Kunst (eds.): Sobre el significado del fuego en los rituales funerarios del Neolítico, Studia Archaeologica 91, Universidad de Valladolid, Valladolid, pp. 99-126.

Herrmann, B. 1976: "Neuere Ergenbnisse zur Beurteilung menschlicher Brandknochen". Zeitschirft für Morphologische Anthropologie 63: 80-89.

Herrmann, B. 1988: "Behandlung von Leichenbrand in Wesen und Methoden der Anthropologie". En R. Knussman (ed.): Wissenschaftstheorie, Geschichte, Morfologische Methoden (I). Gustav Fischer. Stuttgart: 576-585.

Herrmann, B.; Grupe, G.; Hummel, S.; Piepenbrink, H. y Schutkowski, H. 1990: Prähistorische Anthropologie. Leitfaden der Feld- und Labormethoden. Springer. Berlin.

Holck, P. 1986: Cremated bones. A medical-anthropological study of an archaeological material on cremation burials. Antropologiske skrifter 1. Anatomical Institute. University of Oslo. Oslo.

Hummel, S.; Schutkowski, H. y Herrmann, B. 1988: "Advances in cremation research". Notes et monographies techniques 24: 177-194.

Idáñez, J. I. 1984: "Incineración parcial en los enterramientos colectivos eneolíticos del Sudeste Español". Actas de la Mesa Redonda sobre Megalitismo Peninsular (Madrid 1984): 165-167. Madrid.

Mays, S. 1998: The archaeology of human bones. Routledge. London.

Pérez Díaz, S.; Ruiz Alonso, M.; López Sáez, J. A. y Zapata, L. 2010: "Dinámica vegetal y antropización en la Sierra de Cantabria (Álava) desde el Neolítico a la Edad del Bronce". Polen 20: 25-40.

Reimer, P. J.; Bard, E.; Bayliss, A.; Beck, J. W.; Blackwell, P. G.; Bronk Ramsey, C.; Grootes, P. M.; Guilderson, T. P.; Haflidason, H.; Hajdas, I.; Hatté, C.; Heaton, T. J.; Hoffmann, D. L.; Hogg, A. G.; Hughen, K. A.; Kaiser, K. F.; Kromer, B.; Manning, S. W.; Niu, M.; Reimer, R. W.; Richards, D. A.; Scott, E. M.; Southon, J. R.; Staff, R. A.; Turney, C. S. M. y van der Plicht, J. 2013: "IntCal13 and Marine13 Radiocarbon Age Calibration Curves 0-50,000 Years cal BP". Radiocarbon 55 (4): 1869-1887. 
Reverte, J. M. 1990: "Posibilidades del estudio antropológico y paleopatológico de las cremaciones". En F. Burillo (ed.): Necrópolis celtibéricas. Actas del II Simposio sobre Celtibéricos (Daroca 1988): 329-336. Zaragoza.

Reverte, J. M. 1991: Antropología forense. Ministerio de Cultura. Madrid.

Rofes, J.; Zuluaga, M. C.; Murelaga, X.; Fernández Eraso, J.; Bailón, S.; Iriarte, M. J.; Ortega, L. A. y Alonso-Olazabal, A. 2013: "Paleoenvironmental reconstruction of the early Neolithic to middle Bronze Age Peña Larga rock shelter (Álava, Spain) from the small mammal record". Quaternary Research 79: $158-167$.

Rojo, M. y Kunst, M. (eds.). Sobre el significado del fuego en los rituales funerarios del Neolítico. Studia Archaeologica 91, Universidad de Valladolid. Valladolid: 65-82.

Sáenz de Buruaga, A., Urbina, J. y Urigoitia, T. 1991/1992: "Pinturas al aire libre en el abrigo de Las Yurdinas (Álava)". Veleia 8: 99-108.

Scheuer, L. y Black, S. 2000. Developmental juvenile osteology. Academic Press. San Diego.

Shipmann, R.; Foster, G. y Schoeninger, M. 1984: "Burnt bones and teeth: an experimental study of color, morphology, crystal structure and shrinkage". Journal of Archaeological Science 11: 307-325.

Susini, A.; Baud, C. A. y Tochon-Danguy, H. J. 1988: "Identification d' un traitement thermique des os Préhistoriques humains". En L. Buchet (ed.): Anthro- pologie et histoire ou Anthropologie historique, Actes des 3èmes Journées Anthropologiques (Valbone 1986). Notes y monographies techniques 24, Centre National de la Recherche Scientifique. Paris: 43-67. Symes, S. A.; Rainwater, C. W.; Chapman, E. N.; Gipson, D. R. y Piper, A. L. 2008: "Patterned thermal destruction of human remains in a forensic setting". En C. Schimidt y S. A. Symes (eds.): The analysis of burned human remains. Elsevier. London: 15-54.

Thurman, M. y Willmore, L. J. 1981: “A replicative cremation experiment". North American Archaeologist 2 (4): 275-283.

Trancho, G. J. 2010: "Análisis antropológico de las necrópolis de cremación”. Revista Española de Antropología Física 31: 205-232.

Ubelaker, D. H. 1989: "The estimation of age at death from immature human bone". En M. Y. Iscan (ed): Age Markers in the human skeleton: 55-70. Charles C. Thomas. Springfield.

Ubelaker, D. H. 2007: Enterramientos humanos: excavación, análisis, interpretación. Munibe supl. 24, Sociedad de Ciencias Aranzadi. San Sebastián.

Wahl, J. 1981: "Beobachtungen zur Verbrennung Menschlicher Leichname". Archäologisches Korrespondenzblatt 11: 271-279.

Zammit, J. 1991: "Les sépultures préhistóriques et le feu: utilisation rituelle, crémation et incineration". Bulletin de la Société Préhistorique Française 88 (3): 70-72. 